\title{
Transient expression of the influenza A virus PB1-F2 protein using a plum pox virus-based vector in Nicotiana benthamiana
}

\author{
M. KAMENCAYOVÁ ${ }^{1}$, I. KOŠÍK' ${ }^{1}$, J. HUNKOVÁ ${ }^{2}$ Z. W. ŠUBR ${ }^{*}$ \\ ${ }^{1}$ Institute of Virology, Slovak Academy of Sciences, Dúbravská cesta 9, 84505 Bratislava, Slovak Republic; ${ }^{2}$ Faculty of Science, \\ Comenius University, Mlynská dolina, 84215 Bratislava, Slovak Republic
}

Received May 12, 2014; accepted July 14, 2014

\begin{abstract}
Summary. - PB1-F2 protein of influenza A virus (IAV) was cloned in a plum pox virus (PPV) genome-based vector and attempts to express it in biolistically transfected Nicotiana benthamiana plants were performed. The vector-insert construct replicated in infected plants properly and was stable during repeated passage by mechanical inoculation, as demonstrated by disease symptoms and immunoblot detection of PPV capsid protein, while PB1-F2-specific band was more faint. We showed that it was due its low solubility. Modification of sample preparation (denaturation/solubilization preceding the centrifugation of cell debris) led to substantial signal enhancement. Maximal level of PB1-F2 expression in plants was observed 12 days post inoculation (dpi). Only $1 \%$ SDS properly solubilized the protein, other detergents were much less efficient. Solubilization with $8 \mathrm{M}$ urea released approximately $50 \%$ of PB1-F2 from the plant tissues, thus the treatment with this removable chaotropic agent may be a good starting point for the purification of the protein for eventual functional studies in the future.
\end{abstract}

Keywords: viral vector; potyvirus; biolistics; heterologous expression

PB1-F2 protein is a pathogenicity determinant of in fluenza A virus (IAV) translated from an alternative (+1) reading frame in the PB1 gene (Chen et al., 2001). It has been shown to target mitochondrial membrane and induce cell death via interactions with mitochondrial membrane proteins (Gibbs et al., 2003; Yamada et al., 2004; Zamarin et al., 2005). Moreover, it plays a role in the IFN type I response modulation (Goffic et al., 2010; Conenello et al., 2011; Dudek et al., 2011; Le Varga et al., 2011). Single mutation in PB1-F2 increased virulence of the IAV (Conenello et al., 2007). The mechanism of action is so far unknown, however, interaction of PB1-F2 with viral RNA polymerase subunit PB1 is proposed to be involved in this process (Mazur et al., 2008; Košík et al., 2011). In vivo, PB1-F2 is very unstable and prone

"Corresponding author. E-mail: Zdeno.Subr.@savba.sk; phone: +421-2-59302-447.

Abbreviations: $\mathrm{dpi}=$ days post inoculation; $\mathrm{IAV}=$ influenza A virus; $\mathrm{PPV}=$ plum pox virus to rapid degradation under physiological conditions (Chen et al., 2001; Schmolke et al., 2011).

Plum pox virus (PPV) belongs to the genus Potyvirus (the family Potyviridae). It has a (+)ssRNA genome with the length of nearly $10 \mathrm{~kb}$, expression of which is based on the polyprotein processing strategy - the product of a single ORF is co- and post-translationally digested by virusencoded proteases (Salvador et al., 2006). Consequently, all viral proteins are produced in equimolar amounts and their actual activity in infected cells depends on their stability (degradation half-life) or modification (e. g. deposition in inclusion bodies).

Insertion of exogenous genes between regions coding for particular viral proteins in the infectious PPV cDNA may lead to production of foreign proteins in infected plants. Several examples of biofarming using potyviral expression vectors have been published (Komarova et al., 2010). Recently, a full-length infectious cDNA clone of the strain PPV-Rec was constructed and adopted as biologically safe 
viral vector for transient expression (Kamencayová and Šubr, 2012; Predajňa et al., 2012). Here we present our attempts to use this PPV-based vector for stable expression of IAV PB1-F2 in plants.

We used the PPV-Rec-based vector pBOR-VT (Kamencayová and Šubr, 2012) constructed by combining the PPV-Rec infectious full-length cDNA clone (Predajňa et al., 2012) and previously prepared vector PPV-NK (FernándezFernández et al., 2001). The complete PB1-F2-coding sequence (261 bp) was amplified from the previously prepared construct pTriEX4 PB1-F2 (Košík et al., 2011) using EX Taq DNA polymerase (TaKaRa) and primers including EagI and $K p n I$ linkers, respectively (underlined in the sequences): AACGGCCGGATGGGACAGGAACAGGATAC, AAG GTACCCTCGAGTTTGCTGAACAACC. The PCR conditions were as follows: initial denaturation at $94^{\circ} \mathrm{C}$ for $3 \mathrm{~min}$, 40 cycles of $94^{\circ} \mathrm{C} / 15 \mathrm{sec}, 58^{\circ} \mathrm{C} / 30 \mathrm{sec}, 72^{\circ} \mathrm{C} / 1 \mathrm{~min}$, and final extension at $72^{\circ} \mathrm{C}$ for $10 \mathrm{~min}$. The PCR product was directly cloned into pGEM-Teasy (Promega), followed by EagI/KpnI cleavage and recloning in frame in pBOR-VT. FastDigest restriction enzymes (Fermentas) were used for DNA cleavage. The resulting plasmid was transformed and multiplied in Escherichia coli JM109 and purified by PureYield Plasmid Miniprep System (Promega). For the clone analysis, colony PCR was applied with the primer pair NCuniFor/NCuniRev (Predajňa et al., 2012) spanning the PPV NIb-CP border, where the foreign gene was inserted. The conditions were identical as described above except the elongation time was $1.5 \mathrm{~min}$ in each cycle. The amplimers were sequence-verified and corresponding correct plasmid clones were used for plant transfection. Two weeks old $N$. benthamiana plants were transfected biolistically by an air-gun technique as described before (Predajňa et al., 2010) and maintained under insect-free conditions at $23^{\circ} \mathrm{C}$ and photoperiod $14 / 10 \mathrm{hr}$. PPV symptoms were visually evaluated 10-15 dpi, crude leaf sap samples were analyzed by SDS-PAGE in $15 \%$ polyacrylamide gel and immunoblotting with anti-PPV polyclonal antibody (Šubr and Matisová, 1999) and anti-PB1-F2 monoclonal antibody AG55, respectively (Krejnusová et al., 2009). Total protein from plant tissues was isolated using TRIzol reagent (Life Technologies) according to the manufacturer's recommendation. For further analysis, total RNA from infected plants was isolated using the NucleoSpin RNA Plant Kit (Macherey-Nagel), random hexamer-primed cDNA synthesis was carried out using AMV reverse transcriptase (Promega), and PCR with primers NCuniFor/NCuniRev was performed as described above.

From the ten clones analyzed by colony PCR, three harbored no insert in the pBOR-VT and three showed sequence defects at the cloning sites resulting in incorrect frame of the inserted fragment (data not shown). N. benthamiana plants were transfected by each of the four clones with correct sequence of the analyzed region. Following transfection,

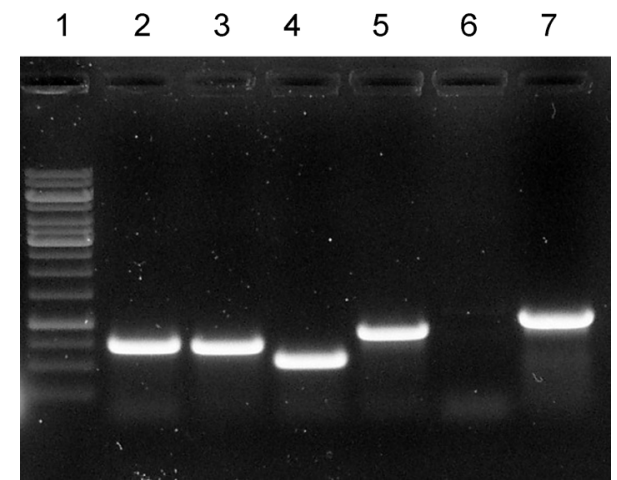

Fig. 1

RT-PCR analysis of plants transfected by four pBOR-VT-PB1-F2 clones $1 \mathrm{~kb}$ DNA Ladder (lane1), clone 1 (lane 2), clone 2 (lane 3), clone 3 (lane 4), clone 4 (lane 5), negative PCR control (lane 6), positive PCR control - plasmid (lane 7).

(a)

(b)

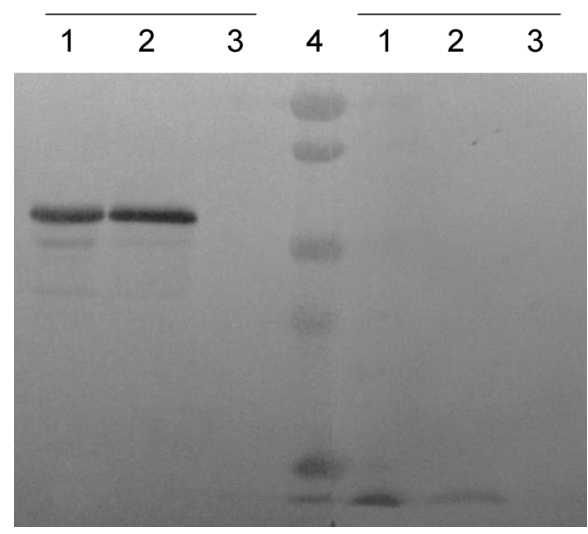

Fig. 2

Immunoblotting analysis of plants transfected by pBOR-VT-PB1 F2 clone 4

Samples collected $7 \mathrm{dpi}$ (lanes 1) or $14 \mathrm{dpi}$ (lanes 2), healthy control (lanes 3), prestained protein MW marker (lane 4). Immunodetection by anti-PPV (a) or anti-PB1-F2 (b) antibodies.

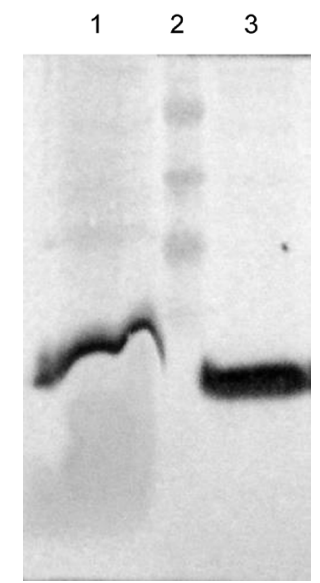

Fig. 3

Comparison of different sample preparation for PB1-F2 detection Immunoblot using anti-PB1-F2 antibody of samples from plants transfected by pBORVT-PB1-F2 10 dpi. Crude sap boiled with SDS prior centrifugation (lane 1), prestained protein MW marker (lane 2), total protein isolated by TRIzol method (lane 3 ). 
three of them showed typical symptoms of PPV infection of the plant, including mosaic and leaf deformation. Symptom manifestation correlated well with the immunoblotting analysis of the crude plant sap using anti-PPV antibody. However, only one sample (clone 4 ) gave a weak signal with anti-PB1-F2 antibody. RT-PCR and sequence analysis from total RNA obtained from $N$. benthamiana confirmed the presence of PB1-F2 sequence only in the clone 4-infected plants. The other clones obviously lost the insert during early multiplication in planta, in the case of clone 3 the deletion included part of the viral CP gene, leading to the loss of infectivity (Fig. 1).

The clone 4 was stable in plants during several passages by mechanical inoculation using the infectious plant sap. PB1F2 concentration detected by immunoblotting, however, remained low and further decreased with the time after infection (Fig. 2). Sampling in very early infection stages (1-4 dpi) showed similar results. It has been demonstrated that PB1-F2 tends to form amyloid fibers in membrane environments (Chevalier et al., 2010). We, therefore, presumed that the majority of produced protein could be part of the insoluble fraction and sedimented together with the cell debris during sample preparation. To prevent this possibility, we added the SDS-containing sample buffer (Laemmli, 1970) directly to the homogenized tissue, vortexed thoroughly and boiled in the water bath for ten minutes. Thereafter the debris was removed by centrifugation and the supernatant analyzed by SDS-PAGE and immunoblotting. Samples prepared by this modified procedure gave notably stronger signal (Fig. 3). In the light of this finding, the aparent concentration drop of PB1-F2 in prolonged infection reflected rather growing insolubility of the protein during its accumulation in the cells than its proteolytic degradation. Excess of chlorophyll in modified samples sometimes partially interferred with detection of the relatively small PB1-F2 $(10.5 \mathrm{kDa})$, even in $15 \%$ polyacrylamide gels. This problem could be fixed by sample preparation using TRIzol reagent (Fig. 3).

Maximal level of PB1-F2 expression in plants was observed $12 \mathrm{dpi}$, its concentration later moderately dropped (data not shown). Our attempts to purify PB1-F2 under native conditions (without SDS) remained, however, unsuccessful. Application of other agents like Triton X-100, CHAPS or guanidinium-Cl was not successful, expressed PB1-F2 resisted to these solubilization attempts. Only 8M urea combined with ultrasonication released approximately $50 \%$ of the protein from the plant tissues. Urea has been applied also for solubilization of PB1-F2 expressed in E. coli (Chevalier et al., 2010).

Here we report the first attempt to express IVA PB1-F2 in $N$. benthamiana using a plant viral vector. Although stable multiplication of the vector PBOR-VT-PB1-F2 in plants was recorded, leading to constitutive transient expression of the desired product, insoluble form of the protein prevented at the moment its efficient extraction and purification for further studies. Denatured recombinant PB1-F2 obtained in sufficient quantity may be applied as an antigen for immunization and production of specific antibodies. Moreover, pilot extraction experiments with urea let us presume the possibility of PB1-F2 purification from the crude soluble fraction in presence of chaotropic agents. It remains a challenge for the future to optimize the conditions of the protein purification. As urea can be removed at the end of the procedure, e.g. by dialysis, it is likely that a fully functional renatured product can be obtained.

Acknowledgements. This work was supported by the grant 2/0008/12 from the Scientific Grant Agency of Ministry of Education and Slovak Academy of Sciences (VEGA).

\section{References}

Chen W, Calvo PA, Malide D, Gibbs J, Schubert U, Bacik I, Basta S, O'Neill R, Schickli J, Palese P, Henklein P, Bennink JR, Yewdell JW (2001): A novel influenza A virus mitochondrial protein that induces cell death. Nat. Med. 7, 1306-1312. http://dx.doi.org/10.1038/nm1201-1306

Chevalier C, Al Bazzal A, VidicJ, Fevrier V, Bourdieu C, Bouguyon E, Le Goffic R, Vautherot JF, Bernard J, Moudjou M, Noinville S, Chich JF, Da Costa B, Rezaei H, Delmas, B (2010): PB1-F2 Influenza A Virus Protein Adopts a $\beta$-Sheet Conformation and Forms Amyloid Fibers in Membrane Environments. J. Biol. Chem. 285, 13233-13243. http:// dx.doi.org/10.1074/jbc.M109.067710

Conenello GM, Tisoncik JR, Rosenzweig E, Varga ZT, Palese P, Katze MG (2011): A Single N66S Mutation in the PB1F2 Protein of Influenza A Virus Increases Virulence by Inhibiting the Early Interferon Response In Vivo. J. Virol. 85, 652-662. http://dx.doi.org/10.1128/JVI.01987-10

Conenello GM, Zamarin D, Perrone LA, Tumpey T, Palese P (2007): A Single Mutation in the PB1-F2 of H5N1 (HK/97) and 1918 Influenza A Viruses Contributes to Increased Virulence. PLoS Pathog. 3, e141. http://dx.doi.org/10.1371/ journal.ppat.0030141

Dudek SE, Wixler L, Nordhoff C, Nordmann A, Anhlan D, Wixler V, Ludwig S (2011): The influenza virus PB1-F2 protein has interferon antagonistic activity. Biol. Chem. 392, 1135-1144. http://dx.doi.org/10.1515/BC.2011.174

Fernández-Fernández MR, Mourino M, Rivera J, Rodriguez F, Plana-Duran J, Garcia JA (2001): Protection of Rabbits against Rabbit Hemorrhagic Disease Virus by Immunization with the VP60 Protein Expressed in Plants with a Potyvirus-Based Vector. Virology 280, 283-291. http:// dx.doi.org/10.1006/viro.2000.0762

Gibbs JS, Malide D, Hornung F, Bennink JR, Yewdell JW (2013): The Influenza A Virus PB1-F2 Protein Targets the Inner Mitochondrial Membrane via a Predicted Basic Amphipathic Helix That Disrupts Mitochondrial Func- 
tion. J. Virol. 77, 7214-7224. http://dx.doi.org/10.1128/ JVI.77.13.7214-7224.2003

Kamencayová M, Šubr Z (2012): Preparation of vectors based on the genome of Plum pox virus PPV-Rec for heterologous gene expression in plants. Acta Fytotech. Zootech. 15, 24-26.

Komarova TV, Baschieri S, Donini M, Marusic C, Benvenuto E, Dorokhov YL (2010): Transient expression systems for plant-derived biopharmaceuticals. Expert Rev. Vaccines 9, 859-876. http://dx.doi.org/10.1586/erv.10.85

Košík I, Krejnusová I, Bystrická M, Poláková K, Russ G (2011): $\mathrm{N}$-terminal region of the $\mathrm{PB} 1-\mathrm{F} 2$ protein is responsible for increased expression of influenza A viral protein PB1. Acta Virol. 55, 45-53. http://dx.doi.org/10.4149/ av 2011 $01 \quad 45$

Krejnusova I, Gocnikova H, Bystricka M, Blaskovicova H, Polakova K, Yewdell J, Bennink J, Russ G (2009): Antibodies to $\mathrm{PB} 1-\mathrm{F} 2$ protein are induced in response to influenza A virus infection. Arch. Virol. 154, 1599-1604. http://dx.doi. org/10.1007/s00705-009-0479-5

Laemmli UK (1970): Cleavage of Structural Proteins during the Assembly of the Head of Bacteriophage T4. Nature 227, 5259, 680-685. http://dx.doi.org/10.1038/227680a 0

Le Goffic R, Bouguyon E, Chevalier C, Vidic J, Da Costa B, Leymarie O, Bourdieu C, Decamps L, Dhorne-Pollet S, Delmas B (2010): Influenza A Virus Protein PB1-F2 Exacerbates IFN- $\beta$ Expression of Human Respiratory Epithelial Cells. J. Immunol. 185, 4812-4823. http://dx.doi.org/10.4049/ jimmunol.0903952

Mazur I, Anhlan D, Mitzner D, Wixler L, Schubert U, Ludwig S (2008): The proapoptotic influenza A virus protein PB1F2 regulates viral polymerase activity by interaction with the PB1 protein. Cell. Microbiol. 10, 1140-1152. http:// dx.doi.org/10.1111/j.1462-5822.2008.01116.x

Predajňa L, Nagyová A, Glasa M, Šubr ZW (2012): Cloning of the complete infectious cDNA of the Plum pox virus strain PPV-Rec. Acta Virol. 56, 135-138. http://dx.doi. org/10.4149/av $2012 \quad 02 \quad 129$

Predajňa L, Nagyová A, Šubr Z (2010): A simple and efficient biolistic procedure of plant transfection with cDNA clons of RNA viruses. Acta Virol. 54, 303-306. http://dx.doi. org/10.4149/av $2010 \quad 04 \quad 303$

Salvador B, Garcia JA, Simon-Mateo C (2006): Causal agent of sharka disease: Plum pox virus genome and function of gene products. EPPO Bull. 36, 229-238. http://dx.doi. org/10.1111/j.1365-2338.2006.00979.x

Schmolke M, Manicassamy B, Pena L, Sutton T, Hai R, Varga ZT, Hale BG, Steel J, Perez DR, Garcia-Sastre A (2011): Differential Contribution of PB1-F2 to the Virulence of Highly Pathogenic H5N1 Influenza A Virus in Mammalian and Avian Species. PLoS Pathog. 7, e1002186. http://dx.doi. org/10.1371/journal.ppat.1002186

Šubr Z, Matisová J (1999): Preparation of diagnostic monoclonal antibodies against two potyviruses. Acta Virol. 43, 255-257.

Varga ZT, Ramos I, Hai R, Schmolke M, Garcia-Sastre A, Fernandez-Sesma A, Palese P (2011): The Influenza Virus Protein PB1-F2 Inhibits the Induction of Type I Interferon at the Level of the MAVS Adaptor Protein. PLoS Pathog. 7, e1002067. http://dx.doi.org/10.1371/journal. ppat.1002067

Yamada H, Chounan R, Higashi Y, Kurihara N, Kido H (2004): Mitochondrial targeting sequence of the influenza A virus PB1-F2 protein and its function in mitochondria. FEBS Lett. 578, 331-336. http://dx.doi.org/10.1016/j. febslet.2004.11.017

Zamarin D, Garcia-Sastre A, Xiao X, Wang R, Palese, P (2005): Influenza Virus PB1-F2 Protein Induces Cell Death through Mitochondrial ANT3 and VDAC1. PLoS Pathog. 1, e4. http://dx.doi.org/10.1371/journal.ppat.0010004 